\title{
Introducing Talented High School Students to Engineering via a Fluid Mechanics Short Course
}

\begin{abstract}
A three-week 'Introduction to Fluid Mechanics and Aerodynamics' course was taught to a diverse group of 12 rising high school seniors during the summer. The class was scheduled for three hours per day, and consisted of a mixture of lecture, hands-on experiments, and activities focused on the societal implications of fluid mechanics. All of the students had only basic physics knowledge, and the majority of the course material was completely new to them. Therefore, each topic was covered from a concepts perspective, with only simple mathematical analyses. In addition to the technical material, the course utilized discussions, presentations, and a field trip to university research facilities to raise awareness of careers in science and engineering and the impact of these fields on quality of life. Course outcomes were assessed through course evaluations, interest surveys, and a concept inventory. The concept inventory was designed to assess the students' fundamental understanding of fluid mechanics principles, and was administered both before and after the course. The interest evaluations inquired about the students' interest in science and engineering, knowledge of careers and college majors, and familiarity with fluid mechanics and its role in society. Student responses generally indicated that the course was effective at increasing their awareness of science, engineering, and fluid mechanics, and their consideration of those subjects as career options. Anonymous post-course student evaluations were consistently high. Because the students voluntarily enrolled in the class, it is believed that a high level of interest in science and engineering already existed for these particular students. The concept inventory and course and interest evaluations clearly showed that the students' knowledge of fluid mechanics and interest in science, technology, engineering, and mathematics (STEM) was strengthened even further by their participation.
\end{abstract}

\section{Background}

The Mississippi Governor's School (MGS) is a three-week residential summer program for rising high school juniors and seniors throughout the state of Mississippi. The school takes place at the Mississippi University for Women, and is administered by faculty members from that institution. Students apply for admission and are selected based on their academic record, as well as demonstrated intellectual, leadership, and creative potential. During the 2008 session, 105 students attended MGS. The program is immersive, and includes scheduled academic, athletic, and social activities each day of the three-week session with the goal of providing a college-like experience for attendees. The academic portion of the program includes both major courses and interest courses. Course proposals are solicited from university, community college, and high school teachers from across the state, and accepted courses make up the MGS curriculum. Students select one major course and one interest area course to attend for the duration of the program. Major courses are held for three hours per day each morning of the session, and are intended to address a focused topic in one of the four general areas of Science, Mathematics, Arts or Humanities. A total of 8 major courses were offered during the 2008 session. Typical examples of major course titles offered included "Faces and Places: A Creative Writing Workshop", "Investigating the Impact of the Media", and "Guitar Studies". Interest area courses are held for a total of 7.5 hours per week in the afternoons, and are intended to be less 
rigorous than major courses, providing the students with an opportunity to broaden their horizons and explore new areas.

Traditionally, the courses offered at MGS have been skewed towards the Arts and Humanities. For example, during the 2008 session, only two major courses and no interest area courses had a science focus, and no courses of either type had a mathematics focus. Aside from the course offering discussed in this paper, the other science-themed course title was: "Cloning, Transgenics, Bioethics: Leadership Decisions for the Future." Because the MGS program included some of the brightest students in the state, and because there was a clear lack of science, technology, engineering and mathematics (STEM) content, the authors identified MGS as a ripe opportunity for promoting engineering education in Mississippi. Such use of summer programs has been previously identified as a potential source of engineering outreach ${ }^{1}$. In fact, similar courses have been proposed for use with summer Governor's School programs in other states ${ }^{2}$.

The authors proposed a major course for the 2008 MGS session entitled "Introduction to Fluid Mechanics and Aerodynamics, which was subsequently accepted and formed part of the MGS curriculum. The course was intended to provide an examination of relevant topics in fluid mechanics and aerodynamics, and their application to problems of interest in the global society of the 21 st century. Instruction included an introduction to the fundamental physical and mathematical principles that govern the behavior of flowing liquids and gases in natural and man-made systems, as well as discussion of applied analysis methods currently used by scientists, engineers and industrial designers. Lectures were supplemented by several hands-on experiments that reinforced the role of fluid physics in the world around us. The course also introduced students to the modern techniques of computational fluid dynamics (CFD), which uses computer-based simulation to investigate and analyze fluid flow systems in a variety of applications. Students solved complex problems using computational software tools that are currently employed by governmental, academic, and industrial research agencies. Several team projects were included, each focusing on a particular aspect of fluid mechanics and aerodynamics relevant to critical environmental, societal, ethical, and economic issues, such as developing alternative energy sources or improving agriculture for developing nations.

It was hoped that the course would excite students about a rigorous STEM discipline by exposing them to aspects that have real impacts on society, and by demonstrating the innovative and creative ways in which fundamental science is used to solve problems on the cutting edge of technology. Fluid mechanics is important to a number of scientific disciplines (e.g. physics, meteorology) and engineering fields (e.g. civil, chemical, mechanical, aerodynamic). However, in contrast to many other scientific subjects such as neuroscience, nanotechnology, or quantum physics, an understanding of its major principles and concepts is accessible to students at the high school level. It was hoped that through their participation students would gain a depth of understanding for this highly interdisciplinary subject well beyond their exposure in high-school physics courses. By stressing economic, environmental, ethical and societal issues in which fluid mechanics plays an important role, students would begin to see how the different aspects of their educational curriculum - such as humanities and social sciences, as well as mathematics and other "hard" sciences_-exist not as standalone compartments, but as parts of a larger whole. In the end, we hoped that the course would inspire students to pursue a career in science or 
engineering, by showcasing the ways in which these careers do indeed put ideas into action to create a brighter future.

The course was attended by 12 students, each of which was a rising junior or senior at a Mississippi high school. The student makeup included three females and one African American male. As discussed above, each of the students attending MGS were chosen based on merit, in a competitive selection process. Surprisingly, the level of science and math preparation varied considerably. Several students were clearly comfortable with basic Calculus concepts, while a few displayed only a minimal mastery of Algebra fundamentals. Because of this variable level of preparation, and because fluid mechanics is an unfamiliar topic to most high school students, the focus was placed on basic underlying physical concepts rather than detailed mathematical treatments.

\section{Course Objectives}

The primary goal of the course was to broaden students' understanding of and appreciation for the role of science and engineering in solving some of the most important problems facing humankind now and in the future. A secondary goal was to encourage students to pursue careers in science and engineering following high school graduation. To this end, the students were introduced to the specific discipline of fluid mechanics and aerodynamics. The third goal was to increase the students' knowledge and understanding in this area. The technical content of the course was intended to provide the students with sufficient depth to gain an appreciation of the topic.

Specific technical and non-technical objectives were for the students to:

- Understand the governing physical principles of single-phase, non-reacting fluid flow, including conservation of mass, the principle of linear momentum (Newton's $2^{\text {nd }}$ Law), and conservation of energy.

- Understand the principles of pressure and velocity and their relationship in flowing fluids (e.g. Bernoulli principle).

- Understand the principle of fluid friction and its application to internal flow (e.g. piping systems) and external flow (e.g. aerodynamic drag).

- Understand the relationship between flowing fluids and forces exerted on solid objects.

- Be able to analytically solve simple fluid mechanics problems including those of fluid statics and fluid dynamics.

- Be able to set up and conduct simple fluid flow experiments that demonstrate fundamental concepts of fluid physics.

- Understand the basic aspects of computational fluid dynamics (CFD) as a means of solving complex fluid flow problems using computer simulations.

- Be able to set up and solve a CFD simulation using the analysis software FLUENT FlowLab, and analyze the results to infer and describe physical concepts. 
- Understand the role of fluid mechanics in addressing critical issues in society, including: improving the economics and quality of life in underdeveloped nations; the development of alternative energy sources; the ethical responsibilities of scientists and engineers; and the advancement of health care science.

- Be able to identify and discuss important roles of science and engineering in general - and fluid mechanics in particular-within the context of broader issues, particularly those discussed in the popular media.

- Better understand the opportunities, responsibilities, and societal impacts of scientists and engineers.

\section{Course Organization and Activities}

The class format varied depending on the activities for any particular day. Conventional aspects of course delivery, including lecture and slide presentations, were used mostly in the early days to cover the fundamentals of fluid mechanics and to lay a foundation for the in-class and out-ofclass projects, experiments, and computer simulations. However, even during the "lecture days", care was taken to present the material in a manner that invited participation from the students. Both of the instructors have had significant experience in creating positive, welcoming learning environments at the undergraduate level, even when the course material is rigorous. Lectures were not one-way. Instead, material presented via notes or overheads was heavily supplemented with active learning activities and open discussion. Other means of content delivery included presentations by the instructors, student presentations, group projects, and simple experiments. The three-week course schedule is shown in Table 1. Note that during the final week classes did not meet on Friday, so the total number of class days was 14.

Table 1. Course Schedule

Day \# Lecture Topics/Activities

1

Fluid Mechanics Introduction and Definitions

Fluid and Flow Properties

Intro to Statics and Dynamics

Interest/Concept Inventory Pre-Assessment

$2 \quad$ Fluid Statics

3 Fluid Dynamics First Principles - Conservation of Mass

Fluid Flow Experiment I - Buoyancy and Archimedes Principle

$4 \quad$ Conservation of Momentum

5 Bernoulli's Equation

$6 \quad$ Viscosity and Fluid Friction

Fluid Flow Experiment II - Linear Momentum Principle

$7 \quad$ Student Presentations - Fluids in the News

Scavenger Hunt - Fluids All Around Us

8 Internal Flow 
Engineering as a Career

9

10

11

12

13

14
Field Trip to Mississippi State University

External Flow - Intro to Aerodynamics

Fluid Flow Experiment III - Internal Flows

Boundary Layers

Student Presentations - Scavenger Hunt Results

Intro to Computational Fluid Dynamics

CFD Group Project

Interest/Concept Inventory Post-Assessment

Course Evaluations

\section{$\underline{\text { Lectures }}$}

New technical material was delivered primarily through a lecture format. An example of a typical hour-long lecture might involve twenty minutes of presentation by the instructor, followed by a five or ten minute "think-pair-share" exercise ${ }^{3}$ in which the students were given a conceptual problem, allowed to work through it in groups of two, and then asked to share their results and conclusions with the class, followed by five to ten minutes of supplemental material such as a video presentation, followed by ten to fifteen minutes of concluding lecture material intended to underscore the major points of the topic. It was our experience that breaking up the presentation of course material into segments of no more than 20 minutes helped students to more successfully process the information, as did presenting material in several different formats.

As mentioned above, an effort was made to ensure that the class atmosphere was exciting, open, and non-threatening. The instructors applied the same methods they have used in their undergraduate courses to insure this. Many of these methods are simple and common sense (smiling, speaking expressively, moving about the classroom, engaging students in a friendly manner) but surprisingly are often neglected by professors even at the university level. While the students at MGS were younger and less mature than typical undergraduates, it was apparent from student feedback that the instructors were successful in creating a fun, low-stress, yet rigorous environment that enhanced the students' experience.

\section{$\underline{\text { Instructor Slide Presentations }}$}

During the three-week term, three slide (i.e. PowerPoint) presentations were given by the instructors. These were intended to supplement the lectures by providing broader content as well as relevant context. The first of these was entitled "Introduction to Fluid Mechanics", and was given to the students on the first day as a means of introducing the course topic. The presentation was a modified version of a similar presentation by Stern et al. ${ }^{4}$. It included information regarding the historical development of fluid mechanics knowledge, the role of fluids in nature, examples of fluid mechanics applications, and a discussion of the methods used to analyze fluid flow systems, including analytical, experimental, and computational techniques. Two example slides from this presentation are shown in Figure 1. 


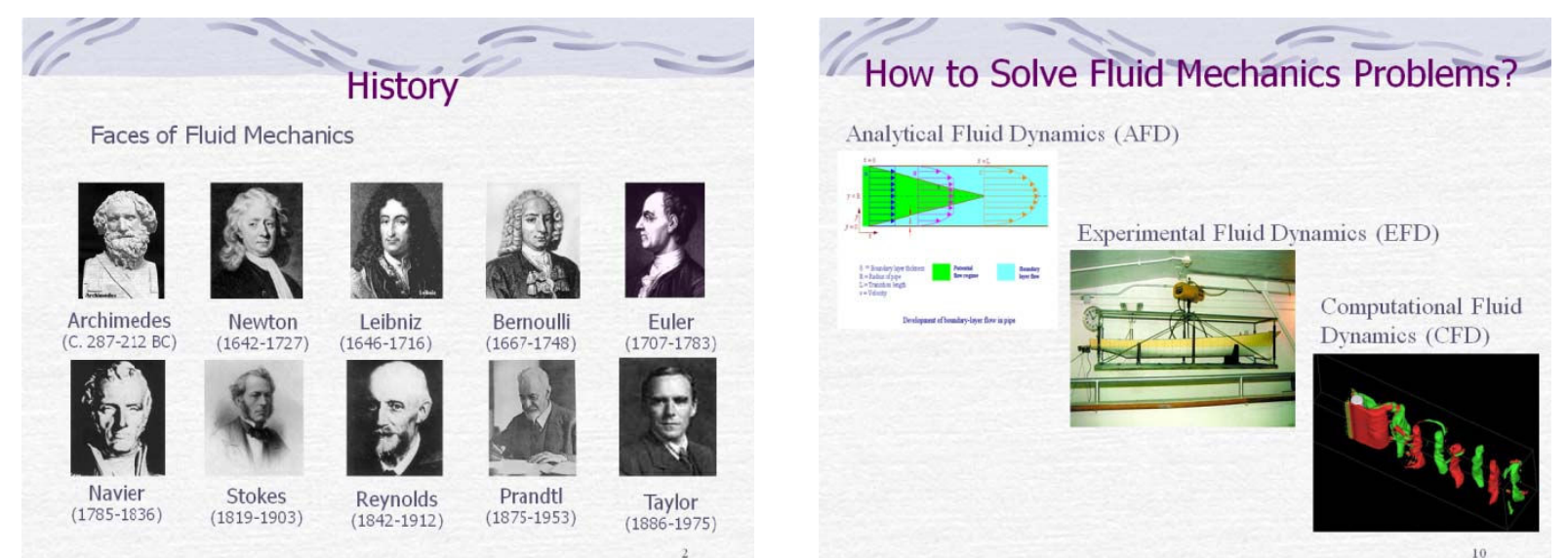

Figure 1. Example slides from instructor presentation "Introduction to Fluid Mechanics".

The second presentation was entitled "What is an Engineer?", and was given to the students on day 8 of the course. The presentation included explanations of the roles engineers play in society and the career opportunities available in engineering, an explanation of the different types of engineers, and salary information. Based on verbal feedback during and after the presentation, much of the information presented was entirely new to this student cohort, despite the fact that they presumably had a preexisting inclination toward STEM careers, based on the fact that they chose this course out of all those offered by MGS and by their responses to the pre-course interest surveys. Two example slides from the second presentation are shown in Figure 2.

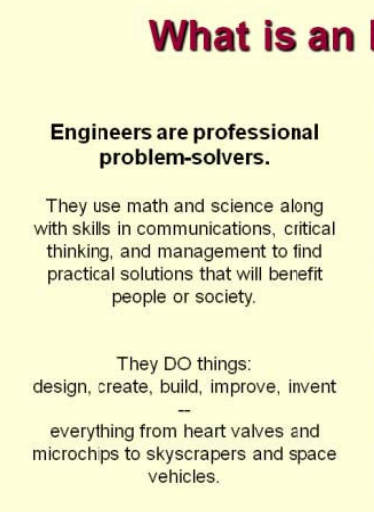

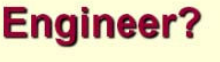

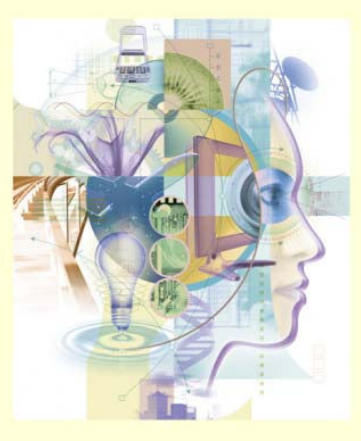

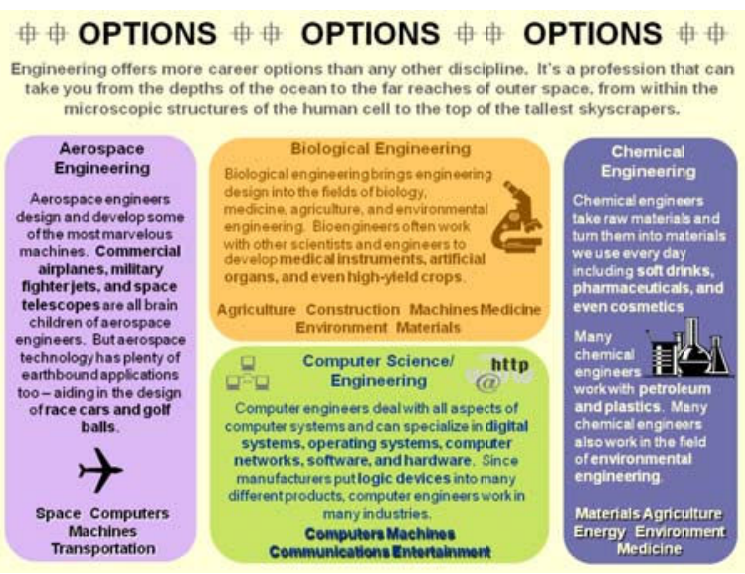

Figure 2. Example slides from instructor presentation "What is an Engineer?".

The third presentation was given on day 12, as a means of introducing the specific topic of computational fluid dynamics (CFD) to the class, prior to assigning a CFD group project to be completed the following class day. The presentation gave a qualitative and heuristic overview of the topic only, including a discussion of scientific and industrial applications in which CFD is 
commonly used. The presentation was entitled "What is CFD?". Example slides are shown in Figure 3.
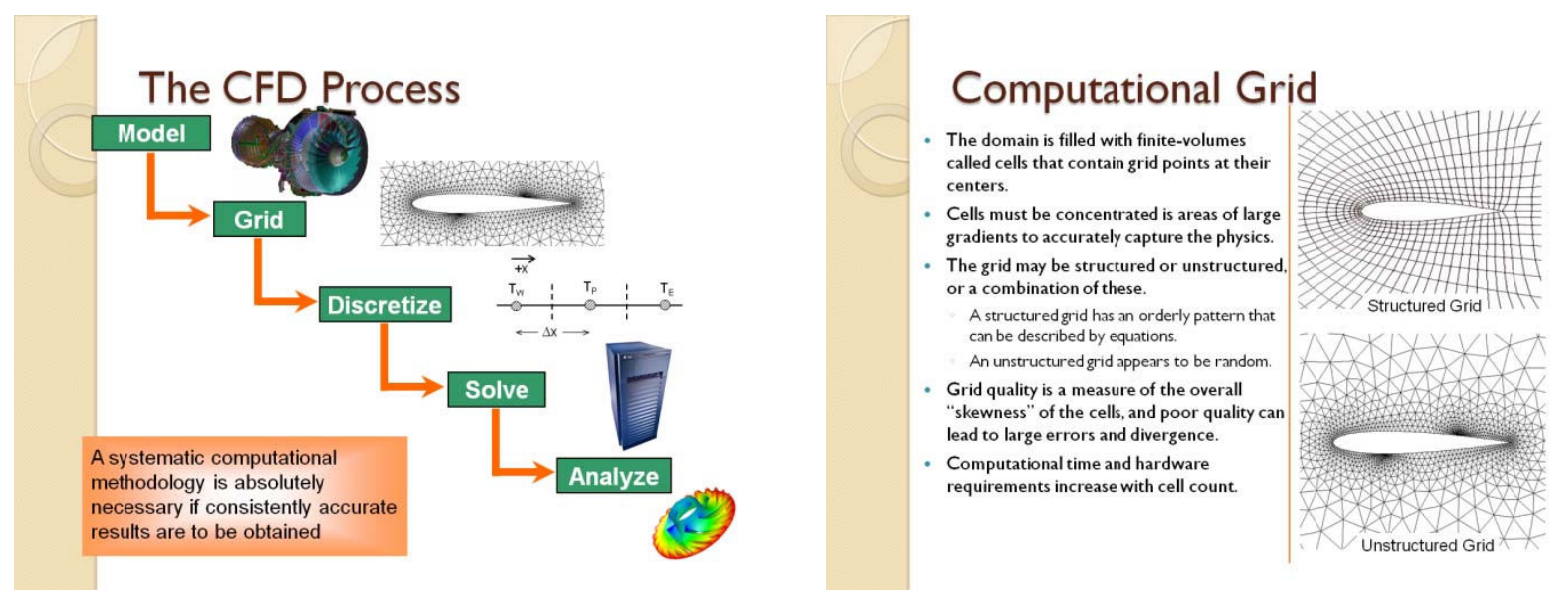

Figure 3. Example slides from instructor presentation "What is CFD?".

\section{$\underline{\text { Student Slide Presentations }}$}

Two student slide presentations were given during the course. One major objective of the presentations was to provide the students with the opportunity to improve their presentation skills, and verbal feedback was given to each student from both the instructors and their fellow classmates.

For the first presentation, entitled "Fluids in the News", students were asked to view Internet news sites such as cnn.com to find news stories in which fluid mechanics plays an important role. The students were asked to find at least two examples, to explain in their own words the principles or impacts of fluid mechanics in the news story, and to explain its overall importance within a societal context. Three representative slides from the "Fluids in the News"

presentations are shown in Figure 4. It should be stressed that while feedback was given to the students, no help was given to the students in preparing or presenting their slides. It was hoped that this exercise would help the students to recognize the importance of fluid mechanics in particular, and science and engineering in general, in many of the important issues discussed in the news media each day. It was clear from discussions after each presentation that the students rarely considered the scientific and technological aspects of many of today's current events. 


\section{Powering Florida with Water}

Researchers are focusing on an untapped resource to power the entire state of Florida: The Gulf Stream.

The idea is a simple one: Put thousands of propellers on the ocean floor that spin from the never-ending current of the ocean, turning turbines that produce energy for use on land.

- As water moves past the angled propellers, it exerts a force at angle to the surface of the propeller, causing it to spin. Much like an airplane propellor or the opposite of an airplane wing

- The large scale of the project is one of its first problems - Each turbine should be 100 feet in diameter. - There will be around ten-thousand of the turbines scattered up and down the coast. Miles of pipe and wire will be needed to Miles of pipe and wire wil be needed to stations
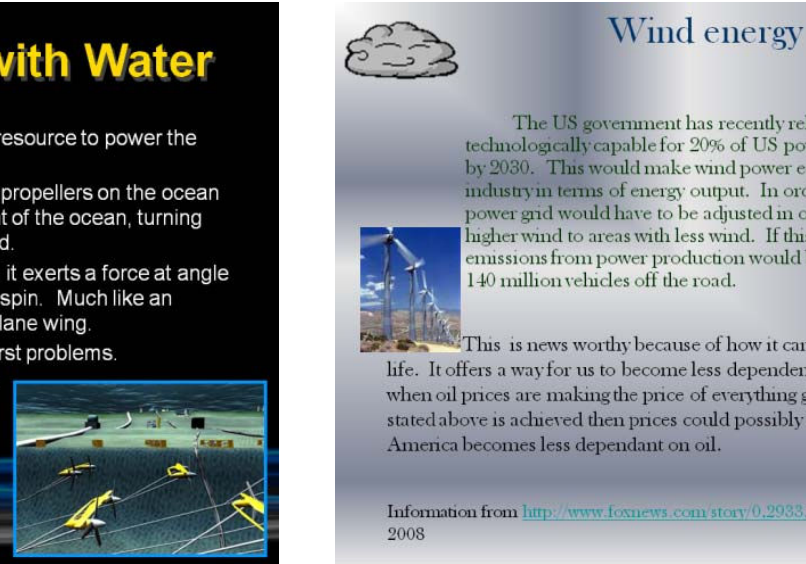

Wind energy

The US government has recently released a report stating that it was techuologically capable for $20 \%$ of US powe: to come from wind power by 2030 . This would make wind power equivalent to the nuclear potver industry in terms of energy output. In order for this to happen though the power grid would have to be adjusted in order to get power from areas of higher wind to areas with less wind. If this was to occur the reduced

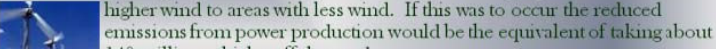
40 million vehicles off the road.

25. This is news worthy because of how it can effect ereryone's life. It offers a way for us to become less dependent on oil especiall when oil prices are making the price of everything go up. If the goal stated above is achieved then prices could possibly become lower as America becomes less dependant on oil.

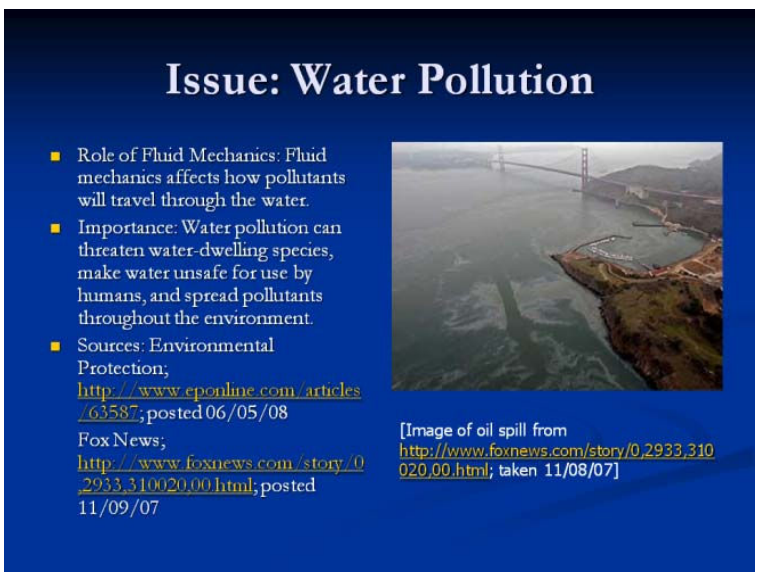

Figure 4. Example slides from "Fluids in the News" student presentations.

The second student presentation showed the results of a "Fluids All Around Us" scavenger hunt. The scavenger hunt itself was undertaken during the second half of the class period on day 7. Students were grouped into four teams of three people each, and each team was given a digital camera. The students explored the campus of the Mississippi University for Women and took pictures of fluid mechanics in action. The goal of the scavenger hunt was twofold. First, to help the students begin to see evidence of scientific principles and engineering applications in their daily lives, and second, to provide them with a fun and leisurely activity at what was approximately the midpoint of the three week course. The students used the digital photos they had taken to create presentations that were shown to the class. Although not asked to do so, several of the groups made an effort to find the most esoteric examples possible. Also, as with the "Fluids in the News" presentations, the students were entirely responsible for preparing and presenting the slides. Example slides from the "Fluids All Around Us" presentations are shown in Figure 5. 

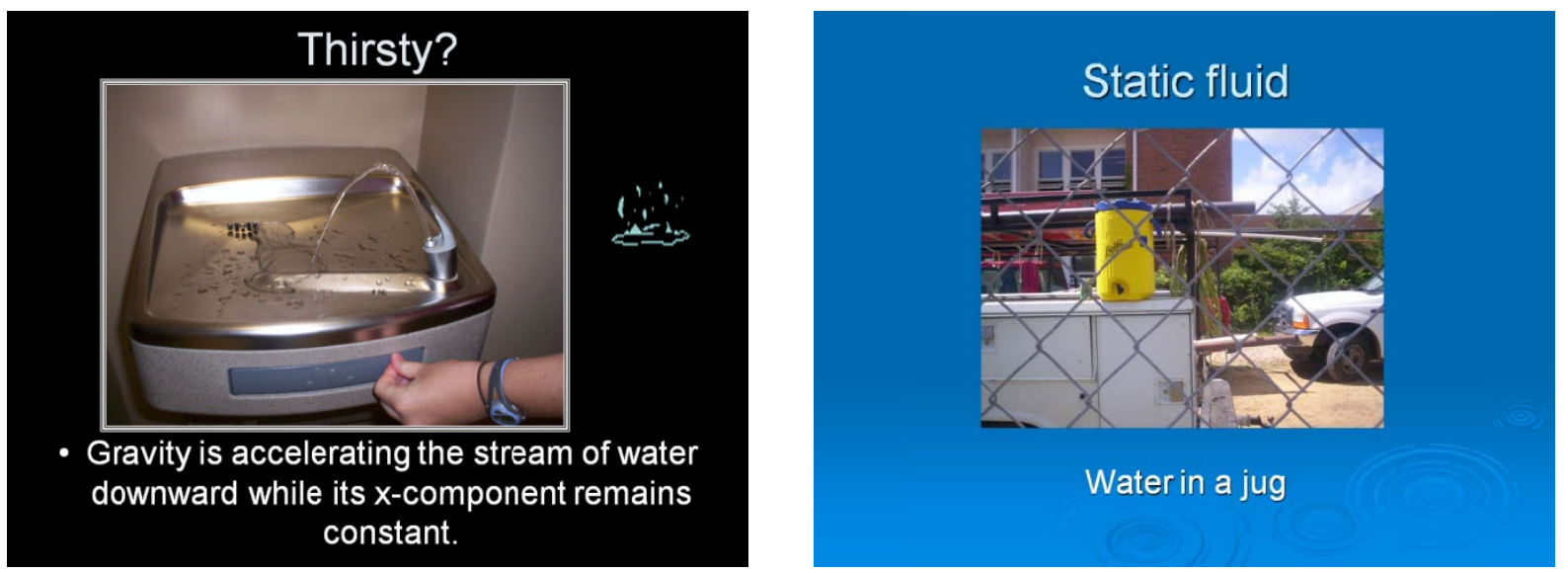

Figure 5. Example slides from "Fluids All Around Us" student presentations.

In addition to the in-class presentations, the entire class gave a group presentation during "Class Night", on the evening of day 14. At MGS, the students in each major course collaborate to give a short presentation that highlights some aspect of what they have learned during the previous three weeks. The Class Night presentations are attended by many of the students' parents, family, and friends, as well as the entire faculty and staff of MGS. As such, an attempt was made to keep the technical level of detail to a minimum. In contrast to the two presentations discussed above, the instructors did provide some input during the preparation of the slides, although the majority of preparation - and all of the actual presentation-was performed by the students in the course. Example slides from the Introduction to Fluid Mechanics and Aerodynamics Class Night presentation are shown in Figure 6.
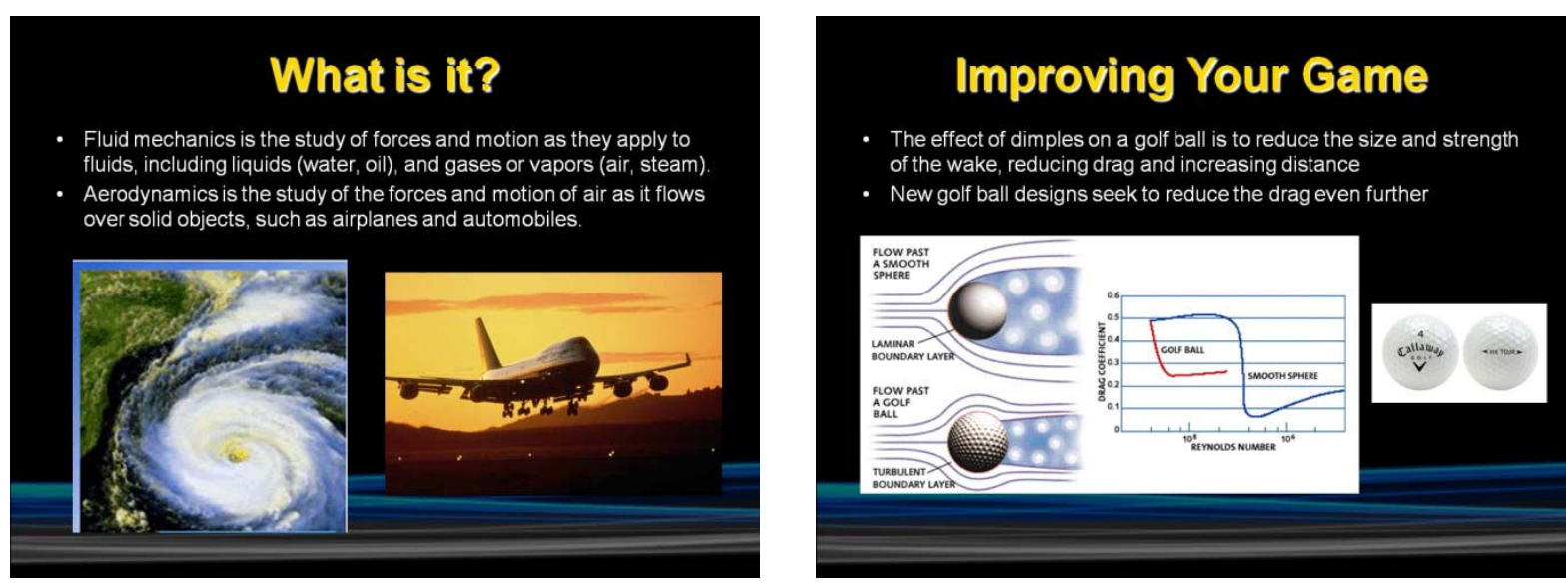

Figure 6. Example slides from "Class Night" student presentation. 


\section{Fluid Flow Experiments}

One effort to make the course content more exciting and accessible involved fluid flow experiments performed by the students. For each of three experiments, the students were divided into three teams of four people each. The students were given all necessary materials and equipment, as well as a set of instructions for performing the experiment. They performed each experiment themselves, under the supervision of the instructors, and reported their results once the experiment was complete. A simplified error analysis was performed by having the students take multiple realizations of the same measurement, eliminate outliers, and determine a mean and standard deviation of their results. Differences in results among the three groups were highlighted, and potential sources of error were discussed.

Each of the experiments was designed to enhance the students' understanding of a particular concept discussed during the lecture portion of the class. The first experiment was entitled "Buoyancy and Archimedes Principle" and supported the Fluid Statics lecture material. Students were supplied with a large (50-gallon) drum filled with water, two steel weights, an empty plastic water jug, a scale to measure weight, liquid measuring cups, and some twine. The experiment was performed in two parts. In the first part, the students were asked to predict whether or not the combination of a weight tied to the empty (and airtight) water jug would float or sink, and, if it would sink, what additional force would be required to keep it off of the bottom. The prediction was based on measured weight and volume of the weights and jug. They did this for both weights (one of which sank when tied to the plastic jug), and compared their predicted force value with their measured values. In the second part of the experiment, the students predicted how much water should be put into the jug so that the weight/jug combination would be neutrally buoyant. They then confirmed their predictions by experimentation. By adding and removing small amounts of water, they iteratively determined how close their predictions were to reality.

The second experiment was entitled "Linear Momentum Principle" and supported the material on that topic. Students were asked to measure the flow rate and velocity of fluid flowing out of a garden hose nozzle and use that information to predict the force that would be necessary to hold the hose/nozzle in static equilibrium when it was curved at a $45^{\circ}$ and $90^{\circ}$ angle. The students made use of a control volume momentum analysis to obtain their predicted force value, and compared the predicted value to measured values. A sample of the instructions and worksheet for this experiment is shown in Appendix A. Similar guidelines were given to the students for the other two experiments.

The third and final experiment was entitled "Internal Flows". It addressed concepts related to fluid friction and pipe flow. The student groups were given three assemblies consisting of a large plastic bucket with an attached tube at the base. The tube diameters varied for each assembly. The students determined the pressure drop in the tube based on the depth of water in the bucket, and measured the flow rate and velocity in the tube while maintaining an approximately constant depth of water in the bucket. The students compared flow rate versus pressure drop and tube diameter, and compared their measured data to predictions based on pipe flow correlations including fluid friction (major and minor losses). A photo of the students performing the experiment is shown in Figure 7. 


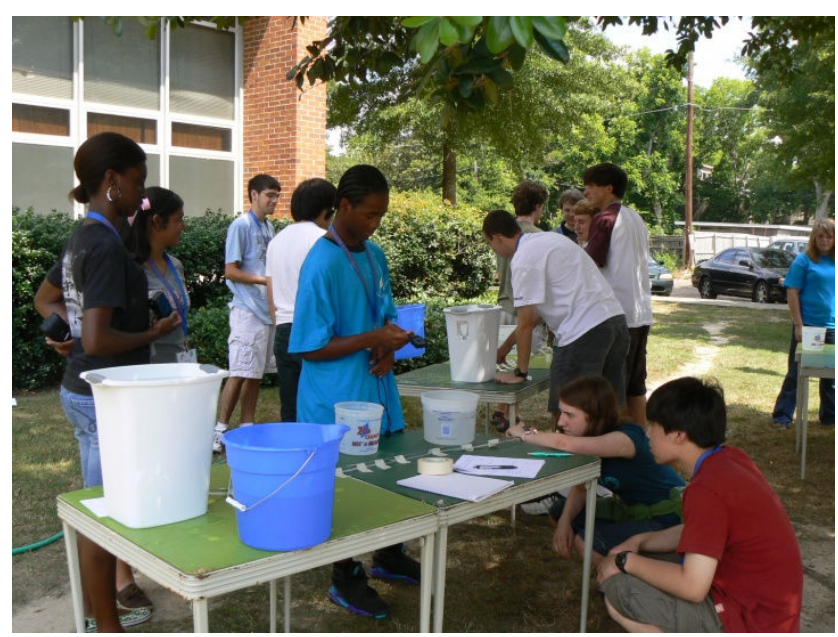

Figure 7. Students performing Experiment \#3: "Internal Flows".

\section{CFD Group Projects}

The computational fluid dynamics (CFD) group projects were performed by four student groups comprised of three people each. CFD has been shown to be an effective means of improving understanding of fluid mechanics concepts among undergraduate students ${ }^{5}$, and it was hoped that a similar impact would be observed for the high school students in this course. The students used FLUENT FlowLab from Ansys, Inc. to predict the lift and drag on an asymmetric airfoil at different angles of attack, for both subsonic and supersonic flow. Each student group was given a set of instructions which they followed to generate a two-dimensional mesh for the given airfoil geometry, set up simulation parameters and boundary conditions, run the flow solver to convergence, and post-process the results. The students documented the results by generating contour plots showing qualitative flow features, including the distribution of pressure and velocity (Figure 8), as well as quantitative plots showing lift and drag coefficient versus angle of attack. The students used the lift and drag curves to identify the angle of attack at which stall occurs. The students incorporated results from the CFD group project in the Class Night presentation discussed above. 

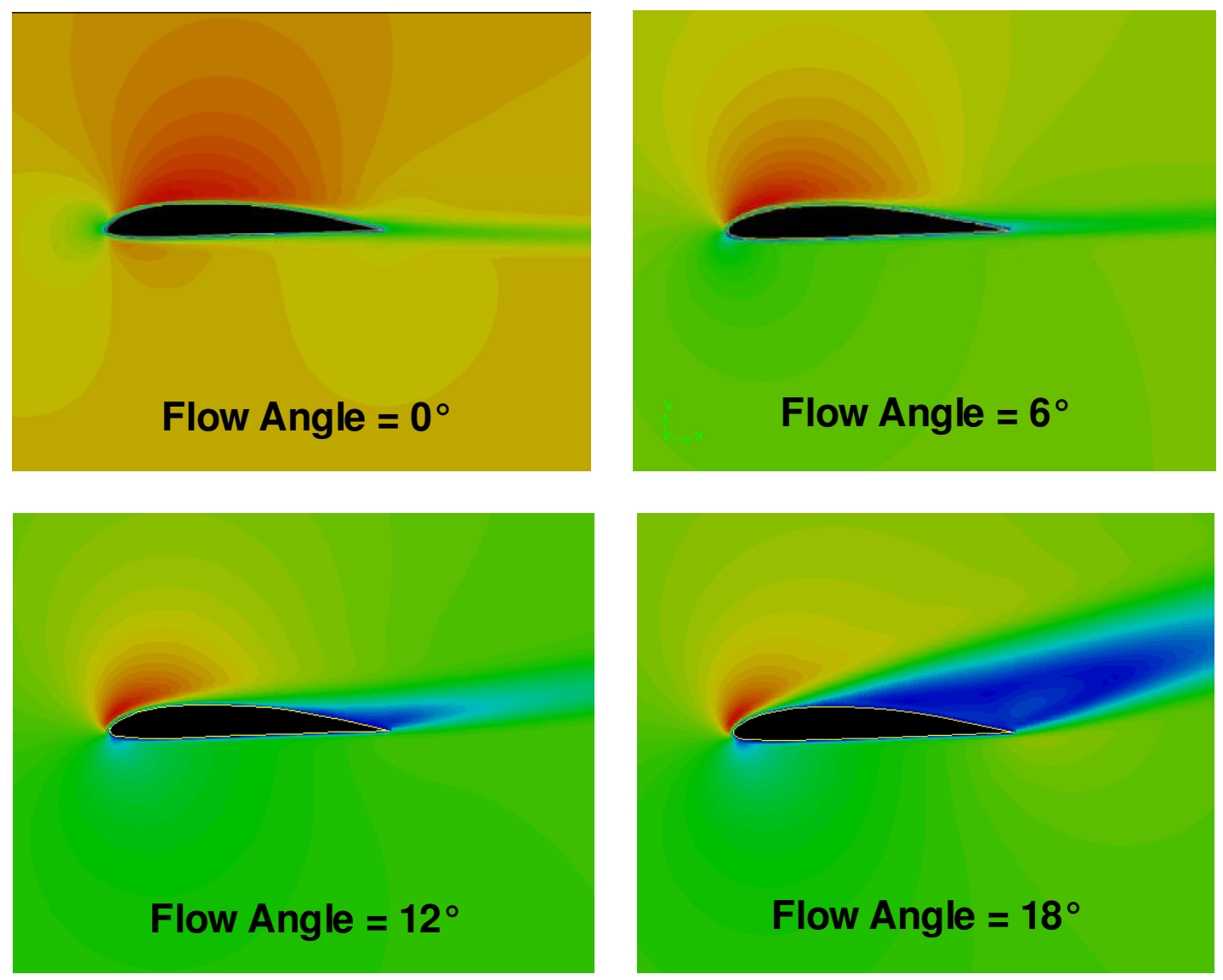

Figure 8. Example results obtained by the students for the CFD Group Project on prediction of lift and drag. Shown are velocity magnitude contours for an asymmetric airfoil at different angles of attack.

\section{Field Trip to Mississippi State University}

The Mississippi Governor's School is held at the Mississippi University for Women, a primarily liberal arts institution located in Columbus, MS. As part of the course, all of the students were taken on a one-day field trip to Mississippi State University, located approximately 20 miles away in Starkville, MS. The students were given guided tours of three research facilities. The first was the Aerospace Engineering wind tunnel laboratory. The tour included both a subsonic and supersonic wind tunnel. The students were shown a demonstration of drag in the subsonic tunnel, including a demonstration of the effects of dimples on the drag for a sphere, a topic that was later discussed in more detail during the lecture on external aerodynamics. The students were also shown a shock wave visualization using the small supersonic tunnel, as well as a demonstration of an unmanned aerial vehicle (UAV) that is part of an ongoing research project at the university. The second tour was of the MSU High Performance Computing Collaboratory, a scientific computing facility that supports research projects in the sciences and engineering. The students were shown large-scale parallel compute clusters and given a demonstration of a full room virtual reality system. They were also introduced to graduate and undergraduate students working on computational research projects, and given a brief explanation of the work that was 
being undertaken. The final tour was of the experimental laboratories in the Swalm School of Chemical Engineering. The students were shown the undergraduate Unit Ops Lab, as well as a polymer engineering research lab. It was apparent from student feedback, both during and after the field trip, that the students enjoyed and appreciated the tours, and that it had a considerable impact on their understanding of engineering research in an academic environment.
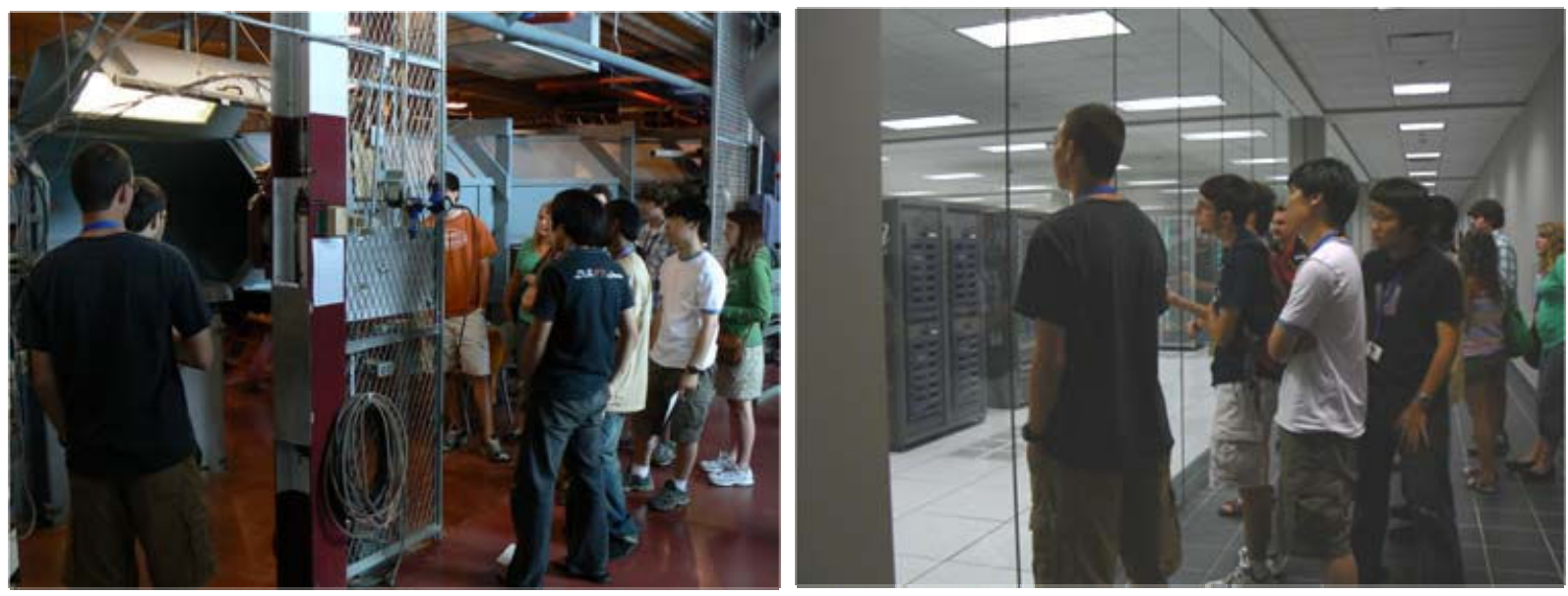

Figure 9. Field trip to Mississippi State University. Left photo: Visiting the Aerospace Engineering wind tunnel laboratory; Right photo: Visiting the High Performance Computing Collaboratory.

\section{Methods of Assessment}

Several methods were used to determine how well the course accomplished the stated objectives of: 1) broadening students' understanding of and appreciation for the role of science and engineering; 2) encouraging students to pursue careers in science and engineering following high school graduation; and 3) increasing the students' knowledge and understanding of fluid mechanics and aerodynamics. Several quantitative and qualitative assessment techniques were used which have been suggested for K-12 engineering outreach programs ${ }^{6}$. Course objectives were assessed through course evaluations (institution and course-specific), interest surveys, a concept inventory administered both pre- and post-course that covered the students' basic understanding of fluid mechanics principles, and follow-up contact with students regarding their post-high school plans. With the exception of the follow-up contact, all other assessments were anonymous and voluntary with the pre-post evaluations correlated using cartoon names. Each of the 12 students elected to participate in the assessment activities.

For each major course taught, a standard course evaluation was administered by the MGS staff. The students responded to nine statements about the course and the instructors. Responses were valued from 1-4, corresponding to "strongly disagree", "disagree", "agree", and "strongly agree". Example statements included "The instructor seemed well prepared for class", "The class was conducted in a way that stimulated interest in the subject", and "In this course, I have learned much and would rate it a good course". The overall average score for all nine statements was 
3.86. The score for the three example statements above was 4.00, 3.73, and 3.91, respectively. In the MGS-administered evaluation, the students were also asked to comment on their favorite part of the class and suggestions for improving the class. The two favorite aspects of the Fluids class were the experiments/hands-on activities and the field trip. Their overwhelming suggestions for improving the class were to increase the length of the class, in terms of number of hours per day, and let them have more time to 'drive' the CFD software.

For the course-specific evaluation (Appendix B), a similar four-level scoring rubric was used with $1=$ disagree, $2=$ somewhat disagree, $3=$ somewhat agree, and $4=$ agree. The mean response was a 3.85 over all questions indicating that the students felt the course had been a positive experience. The highest scores were given to questions $1,3,5$, and 7 and indicated that hands-on activities and 'human factors', including communication between the instructors and the students and lecture style, had a significant impact on the students' evaluation of the course. From their responses, the students felt that the visual and active learning tools (e.g., visual images, experiments, CFD simulations, scavenger hunt, 'fluids in the news') used in the course had significantly improved their interest (4.45/5) and their understanding (4.42/5) of fluid mechanics.

A fluid mechanics concept inventory (CI) was prepared from undergraduate fluid concept inventories available on the $\mathrm{Web}^{7}$. The $\mathrm{CI}$ consisted of 17 questions with multiple choice answers. The instructors attempted to select questions which tested the most basic fluid mechanics principles, recognizing that these were high school students and that they had perhaps not been exposed to physics at this point in their curriculum. Prior to the course, the average class score for the CI was $\sim 35 \%$. The class scored $\sim 46 \%$ on the CI after taking the course, giving an average improvement of $\sim 37 \%$. It was found that 7 of the 11 students (64\%) improved their CI scores over the duration of the 3-week course. Of these students, the average improvement was $67.5 \%$. It was felt that this was a significant improvement over a 3-week course (only 45 student contact hours) in an entirely new subject area.

The interest and self-perceived understanding surveys (Appendix C) asked eight questions related to science and engineering interest, knowledge of careers and options, and knowledge/familiarity of fluid mechanics and its role in society. They were meant to assess the effectiveness of the course in increasing students' awareness of science, engineering, and fluid mechanics, and their consideration of those subjects as career options. Evaluations were given to the students at the beginning and at the end of the course. For each question the students chose from four responses: 'disagree', 'somewhat disagree', 'somewhat agree', and 'agree'. As above, those choices were given integer point values ranging from 1 (disagree) to 4 (agree). Table 2 provides a summary of the student responses for the interest evaluations. For each question a positive change was observed between the pre- and post-evaluations. The average increase was 0.84 . Perhaps not surprisingly, the largest increases were seen for statements related to understanding of different engineering disciplines (4), and statements specifically related to understanding of fluid mechanics $(6,7)$. 
Table 2. Summary of Interest Evaluation Responses

\begin{tabular}{|c|c|c|c|}
\hline Statement & Pre-Course Avg. & Post-Course Avg. & Change \\
\hline 1) I enjoy science and mathematics. & 3.91 & 4.00 & +0.09 \\
\hline $\begin{array}{l}\text { 2) I am interested in pursuing a career in science or } \\
\text { mathematics. }\end{array}$ & 3.64 & 3.91 & +0.27 \\
\hline 3) I am interested in pursuing a career in engineering. & 3.36 & 3.64 & +0.27 \\
\hline $\begin{array}{l}\text { 4) I know about the different engineering disciplines } \\
\text { and the topics covered by each. }\end{array}$ & 2.55 & 3.73 & +1.18 \\
\hline 5) I have a good idea of engineering career options. & 2.91 & 3.64 & +0.73 \\
\hline $\begin{array}{l}\text { 6) I have heard about and could describe the majority } \\
\text { of these concepts: conservation of mass, Newton's } \\
2^{\text {nd }} \text { law, conservation of energy, Bernoulli's } \\
\text { equation, computational fluid dynamics. }\end{array}$ & 2.36 & 3.82 & +1.45 \\
\hline $\begin{array}{l}\text { 7) I understand the role of fluid mechanics in } \\
\text { addressing critical issues in society. }\end{array}$ & 2.09 & 3.82 & +1.73 \\
\hline $\begin{array}{l}\text { 8) I feel comfortable with my technical communication } \\
\text { skills. }\end{array}$ & 2.55 & 3.55 & +1.00 \\
\hline
\end{tabular}

The instructors have been able to follow-up with 11 of the 12 students who participated in the course. Of these all are enrolled or accepted (still in high school) to a 4-year college or university. The major selections of the students are: 8 in engineering, 1 in biology/pre-medicine, 1 in finance, and 1 undecided. The students all responded positively and with enthusiasm to the impact of the Summer 2008 MGS Fluids course on their interest in STEM fields.

The evaluation results indicate that the three goals of the course were achieved to some degree. The primary goal-broadening students' understanding and appreciation of science and engineering - is indicated by student responses to the interest evaluations. In particular, the substantial increase in pre- and post-evaluation student response scores for statements 4,5 , and 7. The second goal-encouraging students to pursue science and engineering careers-is indicated by interest evaluation responses to statements 1-3, and by the follow up contacts with the student participants. The third goal of increasing students' knowledge and understanding of fluid mechanics is indicated by interest evaluation statement 6 , and by the results of the pre- and post-course concept inventories. These conclusions are also supported by the student responses on the course evaluations.

\section{Recommendations for Course Improvement}

Based on the student feedback, post course assessment, and the instructors' own observations, the course was a success. However, upon reflection, a number of potential improvements were identified. These improvements will be implemented if the instructors teach another session of the course at MGS. They include:

- Modification of the course name. In contrast to other courses at MGS, the title "Introduction to Fluid Mechanics and Aerodynamics" may have been somewhat intimidating to some students. The interest surveys taken by the students at the beginning of the course indicate an already strong interest in science and mathematics among the participants. It is quite 
possible that the course title (and catalog description) discouraged students less comfortable and/or familiar with scientific and mathematical subject matter from enrolling.

- Changes to overall course organization. As evidenced in Table 1, the first part of the course consisted primarily of lectures and instructor slide presentations. During the entire first week, the only other activity was the first experiment on buoyancy and the initial concept and interest inventories on day 1 . However, formal and informal feedback indicated that the nonclassroom activities generated the most interest and excitement among the students. It was also apparent that the students struggled to maintain focus for the entire three hour class day when only lecture material was presented. We believe that it would be most effective to include at least one non-lecture activity on each day. To accomplish these activities in the allowed timeframe, the overall amount of technical material would likely need to be reduced.

- Increase in the number of fluid flow experiments. The instructors judged that the two most successful parts of the course, in terms of generating interest and excitement among the participants, were the field trip and the fluid flow experiments. In retrospect, it would have been more effective to include more hands-on experiments and fewer lectures. Future incarnations of the course will likely include additional experiments on the subjects of "Bernoulli's Equation", "Lift and Drag", and/or "Fluid Turbulence".

\section{Conclusions}

The course "Introduction to Fluid Mechanics and Aerodynamics", taught during the 2008 session of the Mississippi Governor's School proved to be a useful engineering outreach exercise for K12 education. The course sought to increase the high school students' technical knowledge of a specific engineering topic as a means of providing a broader appreciation of and interest in science and engineering in general. Course activities were structured in an effort to provide a rigorous learning experience while simultaneously exposing students to information on engineering career opportunities and the role of science and technology in society. The use of varied learning activities significantly enhanced the students' experience.

Student enrollment in the course was voluntary. Also, the student population from which the course participants were taken is by definition a group with high academic achievement. For these reasons, it is likely that participants already had considerable interest in science and engineering. Nevertheless, it is apparent that their experiences in this course strengthened their initial interest. Likewise, it is clear from student feedback that the course had a significant impact on either solidifying existing plans for pursuing engineering in college, or persuading the students to consider science or engineering majors if they had not done so previously.

\section{Acknowledgements}

This work was supported by NSF (CBET0556308) and the Mississippi Governor's School. 


\section{Bibliography}

1. A.T. Jeffers, A.G. Safferman and S.I. Safferman, 2004, "Understanding K-12 engineering outreach programs," Journal of Professional Issues in Engineering Education and Practice, v. 130, n. 2, pp. 95-108.

2. C.D. Poinke and J.R. Parsons, 1998, "Introduction to engineering problem solving and design for high school students in the Tennessee Governor's School for the Sciences," ASEE Annual Conference Proceedings.

3. R.M. Felder and R. Brent, 2003, "Learning by doing," Chemical Engineering Education, v. 37, n. 4, pp. 282283.

4. F. Stern, T. Xing, J. Shao and S. Ghosh, "Introduction to Fluid Mechanics,"

http://www.icaen.uiowa.edu/ fluids/Posting/Lecture\%20note/FluidDynamics.ppt.

5. D.M. Fraser, R. Pillay, L. Tjatindi and J.M. Case, 2007, "Enhancing the learning of fluid mechanics using computer simulations," Journal of Engineering Education, v. 96, n. 4, pp. 381-388.

6. S.J. Poole, J.L Degrazia and J.F. Sullivan, 2001, “Assessing K-12 pre-engineering outreach programs," Journal of Engineering Education, v. 90, n. 1, pp. 43-48.

7. Martin, Mitchell, Jacobi, and Newell, Fluid Mechanic Inventory, www.foundationcoalition.org/home/keycomponents/concept/index.html, accessed 05/27/2008. 


\section{Appendix A}

\section{Experiment \#2: Linear Momentum}

Introduction

The goal of this experiment is to determine the force required to accelerate a fluid via both a change in direction and an increase in speed.

The fluid is water. Initially it flows vertically downward (-y direction) in a flexible hose. The geometry of the hose causes the water to be turned so that it exits the hose with a horizontal $(+x$ direction) component of motion. Additionally, a nozzle is attached to the hose with a smaller exit area than the hose diameter. See the schematics below.

\section{$\underline{\text { Schematics }}$}

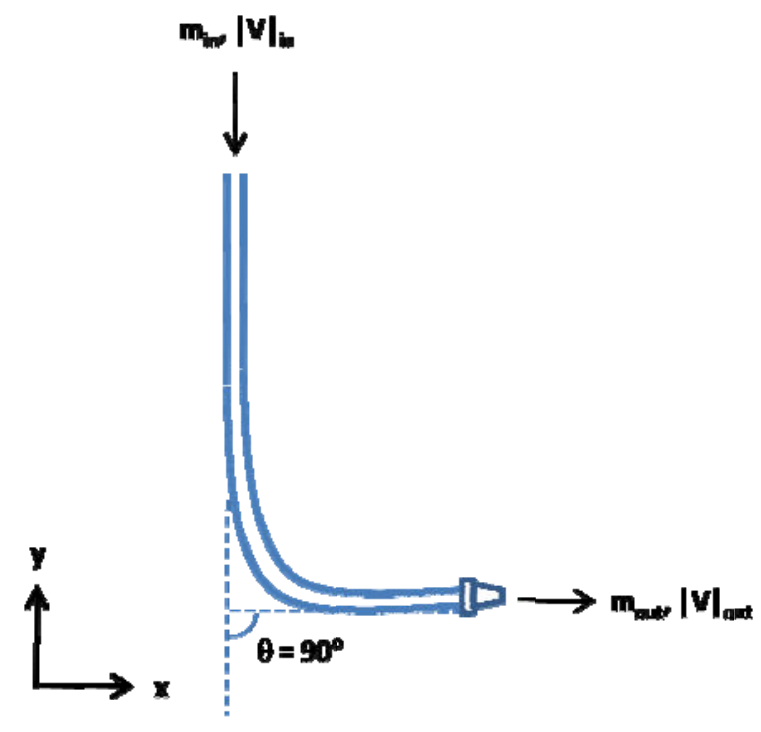

Case 1: $90^{\circ}$ tum (horizontal exit flow)

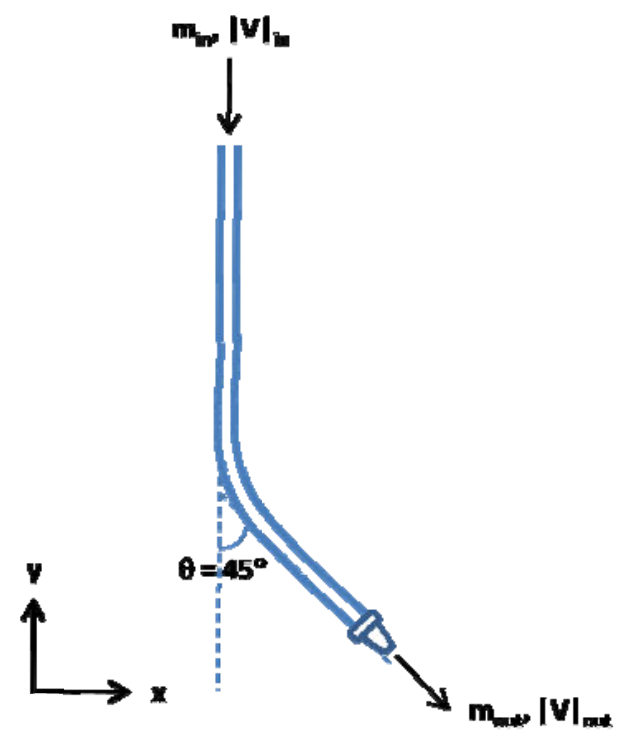

Case 2: $45^{\circ}$ turn (horizontal and vertical exit flow)

Concept Questions (prior to the experiment)

1. For both cases, is out less than / greater than / equal to in?

2. For both cases, is $\mid \mathrm{VI}$ out less than / greater than / equal to $|\mathrm{V}|_{\text {in }}$ ?

3. Considering the $\mathrm{x}$-direction momentum balance, in what direction $(+\mathrm{x}$ or $-\mathrm{x})$ is force being applied to the water by the hose \& nozzle?

4. In what direction is force being applied to the hose \& nozzle by the water?

5. What direction $(+\mathrm{x}$ or $-\mathrm{x})$ must an additional force be applied to the hose to maintain static equilibrium? 


\section{Experimental Procedure}

Step 1: Experimentally measure the volumetric flow rate, the nozzle exit area, and the force exerted by the water on the hose and nozzle.

(a) Using a large bucket and a stopwatch, determine the volume of water that leaves the nozzle over a period of time (use $\sim 10-20$ seconds). Use the volume demarcations on the bucket to determine the volume of water collected and the stopwatch to determine the collection time. In order to reduce the uncertainty of these measurements, repeat the measurement 5 times recording the volume of water and the time for each measurement and calculating the volumetric flow rate $(\mathrm{Q})$.

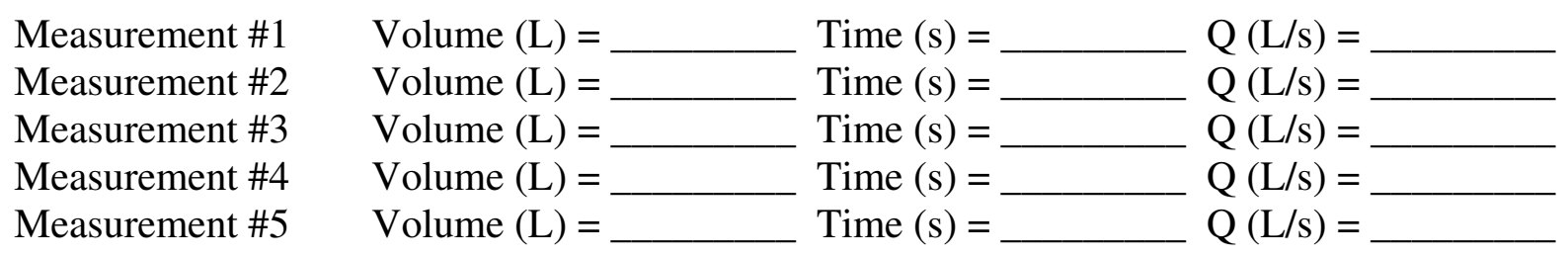

(b) Using the measuring tape, measure the diameter of the nozzle opening. To reduce the uncertainty of the measurement, have each team member replicate the measurement. (Do not tell each other your measurement until all three have been taken.) Convert your individual measurements from inches to meters (using $0.0254 \mathrm{~m}=1 \mathrm{in}$ ) and then calculate the nozzle exit area (using $\mathrm{A}=\pi \mathrm{D}^{2} / 4$ ).

Team Member \#1 Diameter (in) $=$ Team Member \#2 Diameter (in) $=$ Diameter $(\mathrm{m})=$ Diameter $(\mathrm{m})=$ $\mathrm{A}\left(\mathrm{m}^{2}\right)=$ Team Member \#3 Diameter (in) $=$ Diameter $(\mathrm{m})=$ $\mathrm{A}\left(\mathrm{m}^{2}\right)=$ $\mathrm{A}\left(\mathrm{m}^{2}\right)=$

(c) Using the (fish) scale, measure the force required to hold the hose in a vertical position. Ensure that the scale is as close to horizontal as possible (in order to measure the $\mathrm{x}$ component of the force), and that the hose upstream of the turn in as close to vertical as possible. Repeat the measurement 5 times for each case $\left(90^{\circ}\right.$ and $\left.45^{\circ}\right)$. Remember that the scale output is mass $(\mathrm{kg})$ and that force can be calculated by multiplying the mass by gravitational acceleration $\left(\mathrm{g}=9.81 \mathrm{~m} / \mathrm{s}^{2}\right)$. [Note: $\mathrm{F}=\mathrm{m} * \mathrm{a}$ and $\mathrm{N}=\mathrm{kg} \cdot \mathrm{m} / \mathrm{s}^{2}$.]

Case 1 (90 degrees)

Measurement \#1 Scale reading $(\mathrm{kg})=$

Measurement \#2 Scale reading $(\mathrm{kg})=$

Measurement \#3 Scale reading $(\mathrm{kg})=$

Measurement \#4 Scale reading $(\mathrm{kg})=$

Measurement \#5 Scale reading $(\mathrm{kg})=$

Case 2 (45 degrees)

Measurement \#1 Scale reading $(\mathrm{kg})=$

Measurement \#2 Scale reading $(\mathrm{kg})=$

Measurement \#3 Scale reading $(\mathrm{kg})=$

Measurement \#4 Scale reading $(\mathrm{kg})=$

Measurement \#5 Scale reading $(\mathrm{kg})=$
Force $(\mathrm{N})=$

Force $(\mathrm{N})=$

Force $(\mathrm{N})=$

Force $(\mathrm{N})=$

Force $(\mathrm{N})=$

Force $(\mathrm{N})=$ Force $(\mathrm{N})=$ Force $(\mathrm{N})=$ Force $(\mathrm{N})=$ Force $(\mathrm{N})=$ 


\section{Step 2: Data Reduction}

(a) For each set of measurements (volumetric flow rate, nozzle exit area, and force) determine if any of the measurements is a statistical "outlier" and should be rejected from the measurement set. You can use the 'calculator' at www.graphpad.com/quickcalcs/ Grubbs1.cfm. Make sure to select an alpha value of 0.05 .

(b) Compute the average measured values (do not include outliers) for volumetric flow rate, nozzle exit area, and force.

$$
\begin{aligned}
& \text { Volumetric flow rate }=\frac{\mathrm{L} / \mathrm{s}}{\mathrm{m}^{2}} \\
& \begin{array}{l}
\text { Nozzle exit area }= \\
\text { Force }= \\
\text { Force }= \\
\mathrm{N} \text { for Case \#1 (90 degree turn) }
\end{array}
\end{aligned}
$$

(c) Compute the mass flow rate using the relationship below. Assume $\rho_{\mathrm{H} 2 \mathrm{O}}=1000 \mathrm{~kg} / \mathrm{m}^{3}$. Remember there are $1000 \mathrm{~L}$ per $1 \mathrm{~m}^{3}$.

$$
\begin{aligned}
& \text { Mass flow rate }(\mathrm{m})=\text { Volumetric flow rate }(\mathrm{Q}) \mathbf{X} \text { Fluid density }(\rho) \\
& \mathrm{m}=\underset{\mathrm{kg} / \mathrm{s}}{ }
\end{aligned}
$$

(d) Estimate the area of the exiting water stream based on the vena contracta effect. See Figure 3.14. Assume a contraction coefficient $\left(\mathrm{C}_{\mathrm{c}}\right)$ of 0.61 .

$$
\mathrm{A}_{\mathrm{j}}=\mathrm{C}_{\mathrm{c}} \mathrm{A}_{\mathrm{h}}=
$$

(e) Estimate the velocity of the exiting water jet, $|\mathrm{V}|_{\mathrm{j}}$, using the following relationship for mass flow rate:

$$
\begin{aligned}
& \mathrm{m}=\rho_{\mathrm{H} 2 \mathrm{O}} \cdot \mathrm{A}_{\mathrm{j}} \cdot \mathrm{V \textrm {I } _ { \mathrm { j } }} \\
& |\mathrm{V}|_{\mathrm{j}}=\longleftarrow \mathrm{m} / \mathrm{s}
\end{aligned}
$$

Step 3: Analysis

(a) Estimate the force exerted on the water by the hose \& nozzle using the x-direction momentum balance:

$$
\begin{aligned}
& F_{x}=m_{\text {out }} \cdot V_{x, \text { out }}-m_{\text {in }} \cdot V_{x, \text { in }} \\
& \text { where } V_{x} \text { is the } x \text {-direction component of the velocity. }
\end{aligned}
$$

Hint: For Case \#2, $\mathrm{V}_{\mathrm{x}, \text { out }}=\mathrm{V}_{\mathrm{j}} \cdot \sin \left(45^{\circ}\right)=0.707 \cdot \mathrm{V}_{\mathrm{j}}$.

$$
\begin{aligned}
& F_{x}= \\
& F_{x}=
\end{aligned}
$$


(b) Compare your estimate in Step 3(a) with the measured force from Step 2(b). Express the difference between the values as a percentage:

$$
\begin{aligned}
& \% \text { Difference }=\left[\left(\mathrm{F}_{\text {estimated }}-\mathrm{F}_{\text {measured }}\right) / \mathrm{F}_{\text {measured }}\right] \times 100 \\
& \% \text { Difference }=\ldots \text { for Case \#1 (90 degree turn }) \\
& \% \text { fifference }=\ldots \text { for Case \#2 (45 degree turn) }
\end{aligned}
$$

Step 4: Comment on your results 


\section{Appendix B}

\section{Course Evaluation Form}

Cartoon Character Name:

Date:

These evaluations are anonymous. Please do not place your name on the form. However, do write down the name of the cartoon character you drew.

Please rate the following statements to reflect your opinions on this course.

\begin{tabular}{|c|c|c|c|c|c|}
\hline & & Disagree & $\begin{array}{l}\text { Somewhat } \\
\text { Disagree }\end{array}$ & $\begin{array}{l}\text { Somewhat } \\
\text { Agree }\end{array}$ & Agree \\
\hline 1) & $\begin{array}{l}\text { My instructors were able to effectively } \\
\text { present the course material. }\end{array}$ & & & & \\
\hline 2) & $\begin{array}{l}\text { My instructors often used activities to } \\
\text { illustrate concepts presented in class. }\end{array}$ & & & & \\
\hline 3) & $\begin{array}{l}\text { Class activities (demonstrations / } \\
\text { experiments / simulations) increased my } \\
\text { understanding of course material } \\
\text { beyond what was presented in the } \\
\text { lectures. }\end{array}$ & & & & \\
\hline 4) & $\begin{array}{l}\text { I was encouraged to consider the } \\
\text { societal impacts (positive and negative) } \\
\text { of engineering applications and } \\
\text { activities. }\end{array}$ & & & & \\
\hline 5) & $\begin{array}{l}\text { I gained an introductory knowledge of } \\
\text { fluid mechanics. }\end{array}$ & & & & \\
\hline 6) & $\begin{array}{l}\text { I gained an introductory knowledge of } \\
\text { computational fluid dynamics (CFD). }\end{array}$ & & & & \\
\hline 7) & $\begin{array}{l}\text { My instructors were personable and I } \\
\text { felt comfortable asking them questions. }\end{array}$ & & & & \\
\hline 8) & $\begin{array}{l}\text { I was encouraged by my instructor to } \\
\text { develop and/or improve my technical } \\
\text { communication skills. }\end{array}$ & & & & \\
\hline 9) & $\begin{array}{l}\text { I was encouraged by the instructors to } \\
\text { synthesize the course information with } \\
\text { information from my previous classes } \\
\text { (e.g., Mathematics, Physics). }\end{array}$ & & & & \\
\hline
\end{tabular}


In addition to lectures, several visual and active learning tools were used in this course. Please score the following according to how helpful they were to your interest in the course concepts.

[A score of $5=$ very helpful, $4=$ helpful, $3=$ neutral, $2=$ not very helpful, and $1=$ not at all helpful].

Visual images (photos/diagrams)

Experiments

CFD Simulations

'Fluids All Around Us' Scavenger Hunt

'Fluids in the News'

In addition to lectures, several visual and active learning tools were used in this course. Please score the following according to how helpful they were to your understanding of the course concepts.

[A score of $5=$ very helpful, $4=$ helpful, $3=$ neutral, $2=$ not very helpful, and $1=$ not at all helpful].

Visual images (photos/diagrams)

Experiments

CFD Simulations

'Fluids All Around Us' Scavenger Hunt

'Fluids in the News' 


\section{Appendix C}

\section{Interest and Self-Perceived Understanding Survey}

Cartoon Character Name:

Date:

(Don't forget this name! You'll need it later in the course.)

These evaluations are anonymous. Please do not place your name on the form. However, do write down the name of the cartoon character you drew.

Please rate the following statements related to your interest in engineering and understanding of fluid mechanics.

\begin{tabular}{|c|c|c|c|c|}
\hline & Disagree & $\begin{array}{c}\text { Somewhat } \\
\text { Disagree }\end{array}$ & $\begin{array}{c}\text { Somewhat } \\
\text { Agree }\end{array}$ & Agree \\
\hline 1) I enjoy science and mathematics. & & & & \\
\hline $\begin{array}{l}\text { 2) I am interested in pursuing a } \\
\text { career in science or mathematics. }\end{array}$ & & & & \\
\hline $\begin{array}{l}\text { 3) I am interested in pursuing a } \\
\text { career in engineering. }\end{array}$ & & & & \\
\hline $\begin{array}{l}\text { 4) I know about the different } \\
\text { engineering disciplines and the } \\
\text { topics covered by each. }\end{array}$ & & & & \\
\hline $\begin{array}{l}\text { 5) I have a good idea of engineering } \\
\text { career options. }\end{array}$ & & & & \\
\hline $\begin{array}{l}\text { 6) I have heard about and could } \\
\text { describe the majority of these } \\
\text { concepts: } \\
\text { conservation of mass, Newton's } \\
2^{\text {nd }} \text { Law, conservation of energy, } \\
\text { Bernoulli equation, } \\
\text { computational fluid dynamics } \\
\text { (CFD) }\end{array}$ & & & & \\
\hline $\begin{array}{l}\text { 7) I understand the role of fluid } \\
\text { mechanics in addressing critical } \\
\text { issues in society. }\end{array}$ & & & & \\
\hline $\begin{array}{l}\text { 8) I feel comfortable with my } \\
\text { technical communication skills } \\
\text { (e.g., technical writing and } \\
\text { reports, presentations) }\end{array}$ & & & & \\
\hline
\end{tabular}

